Canadian

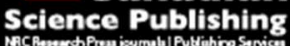

Applied Physiology, Nutrition, and Metabolism Physiologie appliquée, nutrition et métabolisme

\title{
Evaluating the Effect of 20-Hydroxyecdysone (20HE) on Mechanistic Target of Rapamycin Complex 1 (mTORC1) Signaling in the Skeletal Muscle and Liver of Rats
}

\begin{tabular}{|r|l|}
\hline Journal: & Applied Physiology, Nutrition, and Metabolism \\
\hline Manuscript ID & apnm-2015-0301.R2 \\
\hline Manuscript Type: & Brief communication \\
\hline Date Submitted by the Author: & $12-$ Sep-2015 \\
\hline Complete List of Authors: & $\begin{array}{l}\text { Anthony, Tracy; Rutgers University, Nutritional Sciences } \\
\text { Mirek, Emily; Rutgers University, Nutritional Sciences } \\
\text { Bargoud, Albert; Rutgers University, Nutritional Sciences } \\
\text { Phillipson-Weiner, Lindsey; Rutgers University, Nutritional Sciences } \\
\text { DeOliveira, Christopher; Rutgers University, Nutritional Sciences } \\
\text { Wetstein, Berish; Rutgers University, Nutritional Sciences } \\
\text { Graf, Brittany; Rutgers University, Plant Biology and Pathology } \\
\text { Kuhn, Peter; Rutgers University, Plant Biology and Pathology } \\
\text { Raskin, Ilya; Rutgers University, Plant Biology and Pathology }\end{array}$ \\
\hline Keyword: & $\begin{array}{l}\text { leucine, mTOR, phytoecdysteroids, ergogenic aids < nutrition, sports } \\
\text { nutrition < nutrition }\end{array}$ \\
\hline & \\
\hline
\end{tabular}


1 Evaluating the Effect of 20-Hydroxyecdysone (20HE) on Mechanistic Target of Rapamycin

2 Complex 1 (mTORC1) Signaling in the Skeletal Muscle and Liver of Rats

4 Anthony, Tracy G. ${ }^{1}$, Mirek, Emily T. ${ }^{1}$, Bargoud, Albert Raouf ${ }^{1}$, Phillipson-Weiner, Lindsey ${ }^{1}$,

5 DeOliveira, Christopher M. ${ }^{1}$, Wetstein, Berish ${ }^{1}$, Graf, Brittany L. ${ }^{2}$, Kuhn, Peter E. ${ }^{2}$, Raskin, Ilya ${ }^{2}$

$6 \quad{ }^{1}$ Department of Nutritional Sciences and ${ }^{2}$ Department of Plant Biology and Pathology, Rutgers

7 University, New Brunswick, NJ 08901

8

9 Corresponding Author:

10 Tracy G. Anthony, PhD

11 Associate Professor

12 Department of Nutritional Sciences

13 Foran Hall Room 166

1459 Dudley Rd.

15 New Brunswick, NJ 08901

$16 \quad 848-932-6331$

17 tracy.anthony@rutgers.edu 


\section{ABSTRACT}

20

Phytoecdysteroids such as 20HE are nutritional supplements marketed as enhancers of lean body mass. In

21 this study the impact of 20HE ingestion on protein kinase B/Akt-mTORC1 signaling in the skeletal

22 muscle and liver of male rats was found to be limited. Bioavailability of 20HE, whether consumed alone

23 or with leucine, also remained low at all doses ingested. Additional work is necessary to clarify $20 \mathrm{HE}$

24 mechanism of action in vivo.

25

26 KEYWORDS

27 Phytoecdysteroids, PKB/Akt, mTOR, 4E-BP1, leucine

28 


\section{INTRODUCTION}

Phytoecdysteroids are a class of polyhydroxylated ketosteroid compounds found in plants and insects. In arthropods, they function as androgens and are involved in reproduction and the molting process (Dinan 2009). In plants, ecdysteroids serve as a defense mechanism in which their ingestion can disrupt an invading insect's hormone balance, resulting in lethal metabolic damage to the invader (Dinan 2009). One of the most commonly studied ecdysteroids, 20-Hydroxyecdysone (20HE), is naturally present in foods such as spinach and quinoa and is marketed as an anabolic agent in various nutritional supplements taken to improve athletic performance (Lafont and Dinan 2003). Ingestion of 20HE reportedly increases the size of muscle fibers in rats (Toth et al. 2008) as well as increased lean body mass in sheep, pigs and quail (Chermnykh et al. 1988; Lafont and Dinan 2003) and is associated with antidiabetic effects in obese mice (Kizelsztein et al. 2009). Reports in the literature claim anabolic effects in animals and humans without androgenicity (Chermnykh et al. 1988; Lafont and Dinan 2003; GorelickFeldman et al. 2008), but one human trial was unable to substantiate the anabolic potential of $20 \mathrm{HE}$

42 (Wilborn et al. 2006).

The molecular pathway mediating 20HE's anabolic potential remains unknown. Despite being classified as a steroid, 20HE is not structurally close enough to androgens to be able to bind to

45 intracellular steroid receptors in humans (Bathori et al. 2008). Instead, it is suggested that 20HE binds to

46 G protein coupled receptors (GPCR) on the plasma membrane (Bathori et al. 2008). An in vitro study

47 showed that ecdysteroids increase protein synthesis in muscle cells through an influx of $\mathrm{Ca}^{2+}$ and subsequent activation of protein kinase B/Akt (Gorelick-Feldman et al. 2010). In this study, the effects of 20HE were suppressed by inhibitors of GPCR, phospholipase C (PLC) and phosphoinositide kinase-3 (PI3K).

Separate from its effects in muscle, other work has described anti-obesity and anti-diabetic effects

52 of $20 \mathrm{HE}$ in mice via reduced hepatic glucose production in association with increased Akt

53 phosphorylation (Kizelsztein et al. 2009). It is unknown if reported changes in hepatic glucose 
54 production by $20 \mathrm{HE}$ are linked in any way to acute activation of Akt. Furthermore, it is unknown if

55 20HE activates downstream anabolic signaling separate from metabolic signaling in liver. There are no 56 studies assessing phosphorylation of Akt by 20HE in vivo.

57 Stimulation of muscle protein synthesis by insulin and/or insulin-like growth factor I (IGF-I) is mediated via PI3K-Akt activation of mammalian target of rapamycin complex 1 (mTORC1) assembly and signal transduction (Laplante and Sabatini 2012). Oral ingestion of amino acids, and in particular leucine, also stimulates mTORC1 assembly and signaling but in a PI3K-Akt-independent mechanism,

61 allowing for a convergence of amino acid and insulin/IGF-I signaling on mTORC1 upon meal feeding

62 (Anthony et al. 2000; Anthony et al. 2001a; Anthony et al. 2001b). Downstream effectors of mTORC1

63 such as eukaryotic initiation factor 4E binding protein 1 (4E-BP1) function to increase the efficiency of mRNA translation initiation. To what extent $20 \mathrm{HE}$ alone or in combination with leucine activates mTORC1 signaling in skeletal muscle and liver is unknown. The objective of this study was to assess the ability of $20 \mathrm{HE}$ to stimulate mTORC1 signaling in skeletal muscle and liver. A more thorough understanding of 20HE's molecular pathway of action in vivo can inform future interventions in humans or animals.

\section{MATERIALS AND METHODS}

\section{1}

72

73

74

75

76

77

78

Animals and Study Design.

All rats were cared for in accordance with the Guide to the Care and Use of Laboratory Animals and all experiments were reviewed and approved by the Institutional Animal Care and Use Committee at Rutgers University. Overnight fasted 4-8 week old male Sprague-Dawley rats ( $\mathrm{n}=5-6$ per group) were randomized to one of three study designs: 1) gavaged with $0,10,50,200 \mathrm{mg} / \mathrm{kg} 20 \mathrm{HE}$ and euthanized 30 min post-gavage; 2) gavaged with $200 \mathrm{mg} / \mathrm{kg} 20 \mathrm{HE}$ or excipient and euthanized at pre-gavage or $30 \mathrm{~min}$, $60 \mathrm{~min}, 120 \mathrm{~min}, 240 \mathrm{~min}$ post-gavage, and 3) administered excipient or $200 \mathrm{mg} / \mathrm{kg} 20 \mathrm{HE}$ alone or in combination with $1.35 \mathrm{~g} / \mathrm{kg}$ L-leucine and euthanized $30 \mathrm{~min}$ post-gavage. In these studies, 3\% DMSO 
was used as excipient in Study 1 and 2 whereas the emulsifier Labrasol (Hu et al. 2001) was the excipient in Study 3. For all studies the volume administered was $1 \mathrm{ml} / 100 \mathrm{~g}$ body weight. Before food removal, rats were maintained in a temperature-controlled $\left(23-25^{\circ} \mathrm{C}\right)$ room with a $12: 12 \mathrm{~h}$ light:dark cycle and freely-provided commercial rodent diet.

Sample collection. Rats were euthanized by decapitation and trunk blood was collected for analysis of serum leucine and 20HE concentrations. The liver and hind-limb muscles (gastrocnemius + plantaris) were quickly extracted, weighed and frozen in liquid nitrogen before storage in a $-80^{\circ} \mathrm{C}$ freezer.

Serum measurements. Serum leucine was analyzed via HPLC using ortho-phthalaldehyde/9fluorenylmethyl chloroformate (OPA/FMOC) derivatized amino acid analysis. Detection was performed according to Agilent protocol app note: 5990-4547EN using Agilent ZORBAX Eclipse Plus C18 column. To quantify bioavailability of $20 \mathrm{HE}, 500 \mu \mathrm{l}$ aliquots of serum samples were extracted with $500 \mu \mathrm{l}$ of butanol three times. The organic layer was dried and dissolved in $100 \mu 1$ of $70 \%$ ethanol; $5 \mu 1$ was injected in LC-MS (5-95\% acetonitrile gradient). A standard curve of $20 \mathrm{HE}(5,10,50 \mathrm{ng})$ was run alongside samples in LC-MS for quantification.

Immunoblot Analysis. Tissue samples were prepared for SDS-PAGE followed by immunoblot analysis as previously described (Anthony et al. 2007). Immunoblots included a tissue sample from rats injected with IGF-I as a positive control for Akt phosphorylation. Membranes were incubated with the following primary antibodies: Akt (p-Thr308), mTORC1 (p-Ser2448), and 4E-BP1. Protein expression was visualized using enhanced chemiluminescence (ECL) and signal intensities were digitally captured using a FluorChem M multiplex imager (ProteinSimple) and band densities were quantitated using imaging software.

Statistics. Data are expressed as means \pm SEM. Experimental results were analyzed by ANOVA using the STATISTICA software package. Differences between group means were assessed by Tukey's post hoc test. The level of significance was set at $\mathrm{P} \leq 0.05$ for all statistical tests. 


\section{RESULTS}

Study 1: 20HE Dose Response

106 Young male rats were overnight (12h) fasted then gavaged with doses of $20 \mathrm{HE}$ that have been cited in the

107 literature as imparting anabolic or metabolically-favorable properties in rodents. The lowest dose

108 administered was twice the dosage used in a previous study reporting anabolic properties, and the highest

109 dose administered was $200 \mathrm{mg} / \mathrm{kg}$, an amount higher than a commonly suggested dose in humans of 200

$110 \mathrm{mg}$ per day, but substantially below the oral LD50 in mice of $>9,000 \mathrm{mg} / \mathrm{kg}$. None of the doses

111 administered significantly altered the phosphorylation states of Akt, mTOR or 4E-BP1 at 30 minutes after

112 ingestion in either the skeletal muscle (Figure 1, A-C) or liver (Figure 2, A-C). Quantification of 20HE

113 from plasma samples showed there were minimal differences in bioavailability among the doses at 30

114 minutes when delivered in 3\% DMSO in saline. Serum 20HE concentrations were detectible only in rats

115 gavaged with 20HE but remained similarly low across all doses $(\sim 0.45 \mathrm{ng} / \mu \mathrm{l})$.

117 Study 2: 20HE Time Course

118 To determine if the effect of 20HE on Akt phosphorylation or mTORC1 signaling in skeletal muscle 119 and/or liver was delayed past 30 minutes, rats were overnight fasted and then administered $200 \mathrm{mg} / \mathrm{kg}$ $12020 \mathrm{HE}$ and euthanized at $30 \mathrm{~min}, 60 \mathrm{~min}, 120 \mathrm{~min}$ and $240 \mathrm{~min}$ following gavage. No changes in the 121 phosphorylation status of Akt, mTOR or 4E-BP1 as compared to untreated controls were noted in either

122 skeletal muscle (Figure 1, D-F) or liver (Figure 2, D-F) over the $4 \mathrm{~h}$ time course except phosphorylation 123 of 4E-BP1 was reduced at $240 \mathrm{~min}$ in skeletal muscle only (Figure 1F). Quantification of 20HE from 124 plasma showed 20HE levels in blood ranged between $0.3-0.5 \mathrm{ng} / \mu \mathrm{l}$ after gavage when delivered in $3 \%$ 125 DMSO in saline.

127 Study 3: Acute Effects of 20HE versus Leucine 
Previous work by this lab and others show that oral administration of $1.35 \mathrm{~g} / \mathrm{kg}$ body weight L-leucine activates mTORC1 signaling in skeletal muscle between 15-60 minutes following ingestion without altering Akt phosphorylation (Anthony et al. 2001a). To compare the impact of 20HE ingestion to that of leucine, mice were orally administered either $20 \mathrm{HE}(200 \mathrm{mg} / \mathrm{kg})$, leucine $(1.35 \mathrm{~g} / \mathrm{kg})$, the combination together, or excipient alone. To improve bioavailability of 20HE, Labrasol was used as the gavage excipient instead of 3\% DMSO in saline. Average serum concentrations of leucine were statistically similar to average serum concentrations of leucine in rats gavaged with $20 \mathrm{HE}$. Serum leucine concentrations rose significantly in rats gavaged with leucine alone and in mice gavaged with leucine plus $20 \mathrm{HE}$ (both $\mathrm{P}<0.05$ as compared to control). While leucine concentrations rose significantly regardless of 20HE consumption, 20HE bioavailability appeared to be improved by Labrasol, though with great variation, for serum levels of $20 \mathrm{HE}$ measured $0.74 \pm 0.076 \mathrm{ng} / \mu \mathrm{l}$ in rats gavaged with $20 \mathrm{HE}+$ leucine compared with $1.52 \pm 1.23 \mathrm{ng} / \mu \mathrm{l}$ in rats gavaged with $20 \mathrm{HE}$ alone. In agreement with previous reports,

140 leucine alone significantly increased phosphorylation of mTOR and 4E-BP1 in both skeletal muscle

141 (Figure 1, H-I) and liver (Figure 2, H-I). On the other hand, ingestion of 20HE alone did not alter

142 mTORC1 signaling in skeletal muscle or liver and slightly dampened stimulation of mTORC1 by leucine

143 in skeletal muscle. Neither leucine nor 20HE altered phosphorylation of Akt in liver or muscle at 30 min 144 when gavaged alone or in combination (Figure 1G, 2G).

\section{DISCUSSION}

Phytoecdysteroids are one of the most abundant steroid classes in nature, are non-toxic to

148 mammals, yet display pleiotropic effects which are potentially beneficial if harnessed properly. Among

149 the postulated health benefits of this class of compounds, increased muscular mass and improved glucose 150 homeostasis is evidenced in both in vitro and in vivo studies (Gorelick-Feldman et al. 2008; Toth et al. 151 2008; Kizelsztein et al. 2009; Gorelick-Feldman et al. 2010; Seidlova-Wuttke et al. 2010). To understand 152 if mTORC1 signaling may contribute to any of these previously reported outcomes, we embarked on a 153 series of experiments evaluating acute effects of $20 \mathrm{HE}$ consumption in the skeletal muscle and liver of 
154

155

156

157

158

159

160

161

162

163

164

165

166

167

168

169

170

171

172

173

174

175

176

177

178

179

male rats. Based on recent reports describing rapid activation of Akt associated with increased protein synthesis in cultured myocytes (Gorelick-Feldman et al. 2010) and reduced hepatic glucose production and body weight in obese mice (Kizelsztein et al. 2009), we hypothesized that activation of Akt by $20 \mathrm{HE}$ leads to increased signaling via the mTORC1 pathway in skeletal muscle and/or liver. Yet, study results did not support this idea, showing that 20HE does not acutely activate Akt phosphorylation or mTORC1 signaling in hind limb muscle or liver. As such, the mechanism to explain potential health benefits of 20HE remains an open question requiring additional exploration. The following narrative offers alternate approaches and additional considerations.

The bioavailability of $20 \mathrm{HE}$ was quite low in these studies and appeared insensitive to increasing doses. While using an excipient such as Labrasol improved bioavailability, this did not result in improved activation of the Akt-mTORC1 pathway at the time points examined. The choice to focus on early time points was based on previous work showing activation of Akt by $20 \mathrm{HE}$ within $4 \mathrm{~h}$ and activation of mTORC1 by leucine within $1 \mathrm{~h}$ (Anthony et al. 2001a; Gorelick-Feldman et al. 2010). A follow-up time course administering $20 \mathrm{HE}$ in combination with calories and/or carbohydrates is warranted to test the idea that $20 \mathrm{HE}$ functions to augment insulin/IGF-I signaling by meal feeding. Interestingly, in the current study provision of leucine in combination with $20 \mathrm{HE}$ results in a dampening of mTORC1 signaling despite elevated circulating leucine. Thus, if $20 \mathrm{HE}$ is to augment the action of another nutrient, it is not likely to be an amino acid-driven pathway. Follow up studies exploring how the food matrix impacts 20HE absorption and potential augmentation of macronutrient metabolism is warranted.

This study contributes importantly to the study of phytoecdysteroids and establishes that acute bioavailability of $20 \mathrm{HE}$ is limited when consumed alone or with leucine. While one interpretation is that the anabolic signaling effect of $20 \mathrm{E}$ is limited by digestibility and absorption, an alternate explanation is that the mechanism of effect is independent of mTOR. Certainly, among the pathways affected by nutritional status, mTORC1 is one of the most important cellular signaling hubs in the body, regulating cell growth, autophagy, and proliferation (Laplante and Sabatini 2012). However, the path to improved body composition does not have to be mediated through mTOR. Alternate mechanisms requiring future 
180 investigation include phospholipase C and cAMP/PKA (Gorelick-Feldman et al. 2010), reducing protein

181 breakdown (e.g., similar to the leucine metabolite $\beta$-Hydroxy $\beta$-Methylbutyrate (Molfino et al. 2013)),

182 altering vitamin D status or action in muscle (Toth et al. 2010) and increasing lipolysis so as to improve

183 lean body mass. In summary, study results show that ingestion of $20 \mathrm{HE}$ does not acutely activate

184 mTORC1 signaling in muscle or liver. Additional work is necessary to clarify the mechanism by which

185 phytoecdysteroids can facilitate muscle growth and liver metabolism in mammals.

187 Conflict of Interest Disclaimer: The authors declare that there are no conflicts of interest.

188

189 ACKNOWLEDGEMENTS

190 The authors gratefully acknowledge the expert technical assistance of Pengxiang She, $\mathrm{PhD}$, Gabriel

191 Wilson, PhD, Rana Al Baghdadi and George Wei. This work was funded by USDA Multistate Project

192 NC1184 and the New Jersey Agricultural Experiment Station at Rutgers University. 


\section{REFERNCES}

Anthony, J., Anthony, T., Kimball, S., and Jefferson, L. 2001a. Signaling pathways involved in translational control of protein synthesis in skeletal muscle by leucine. J. Nutr. 131: 856S-860S. PMID: 11238774.

Anthony, J., Yoshizawa, F., Anthony, T., Vary, T., Jefferson, L., and Kimball, S. 2000. Leucine stimulates translation initiation in skeletal muscle of postabsorptive rats via a rapamycinsensitive pathway. J. Nutr. 130(10): 2413-2419. PMID: 11015466.

Anthony, T., Anthony, J., Yoshizawa, F., Kimball, S., and Jefferson, L. 2001b. Oral administration of leucine stimulates ribosomal protein mRNA translation but not global rates of protein synthesis in the liver of rats. J. Nutr. 131(4): 1171-1176. PMID: 11285321.

Anthony, T.G., McDaniel, B.J., Knoll, P., Bunpo, P., Paul, G.L., and McNurlan, M.A. 2007. Feeding meals containing soy or whey protein after exercise stimulates protein synthesis and translation initiation in the skeletal muscle of male rats. J. Nutr. 137(2): 357-362.

$$
\text { PMID:17237311. }
$$

Bathori, M., Toth, N., Hunyadi, A., Marki, A., and Zador, E. 2008. Phytoecdysteroids and anabolic-androgenic steroids--structure and effects on humans. Curr. Medicinal Chem. 15(1): 7591. doi: 10.2174/092986708783330674\#sthash.Ceoi3oxK.dpuf. PMID: 18220764 
217 Chermnykh, N.S., Shimanovskii, N.L., Shutko, G.V., and Syrov, V.N. 1988. [The action of

218 methandrostenolone and ecdysterone on the physical endurance of animals and on protein

219 metabolism in the skeletal muscles]. Farmakol. Toksikol. 51(6): 57-60. PMID: 3234543.

220

221 Dinan, L. 2009. The Karlson Lecture. Phytoecdysteroids: what use are they? Arch. Insect

222 Biochem. Physiol. 72(3): 126-141. doi: 10.1002/arch.20334. PMID: 19771554.

223

224 Gorelick-Feldman, J., Cohick, W., and Raskin, I. 2010. Ecdysteroids elicit a rapid Ca2+ flux

225 leading to Akt activation and increased protein synthesis in skeletal muscle cells. Steroids

226 75(10): 632-637. doi: 10.1016/j.steroids.2010.03.008. PMID: 20363237.

227

228 Gorelick-Feldman, J., Maclean, D., Ilic, N., Poulev, A., Lila, M.A., Cheng, D., and Raskin, I.

229 2008. Phytoecdysteroids increase protein synthesis in skeletal muscle cells. J. Agric. Food.

230 Chem. 56(10): 3532-3537. doi: 10.1021/jf073059z. PMID: 18444661.

231

232 Hu, Z., Tawa, R., Konishi, T., Shibata, N., and Takada, K. 2001. A novel emulsifier, labrasol,

233 enhances gastrointestinal absorption of gentamicin. Life Sci. 69(24): 2899-2910. PMID:

23411720093.

235

236 Kizelsztein, P., Govorko, D., Komarnytsky, S., Evans, A., Wang, Z., Cefalu, W.T., and Raskin,

237 I. 2009. 20-Hydroxyecdysone decreases weight and hyperglycemia in a diet-induced obesity

238 mice model. Am. J. Physiol. Endocrinol. Metab. 296(3): E433-E439. doi:

239 10.1152/ajpendo.90772.2008. PMID: 19126784. 
241 Lafont, R. and Dinan, L. 2003. Practical uses for ecdysteroids in mammals including humans: an 242 update. J. Insect Sci. 3: 7. PMID:15844229.

243

244

245

246

247

248

249

250

251

252

253

254

255

256

257

258

259

260

261

262

Laplante, M. and Sabatini, D.M. 2012. mTOR signaling in growth control and disease. Cell 149(2): 274-293. doi: 10.1016/j.cell.2012.03.017. PMID: 22500797.

Molfino, A., Gioia, G., Rossi Fanelli, F., and Muscaritoli, M. 2013. Beta-hydroxy-betamethylbutyrate supplementation in health and disease: a systematic review of randomized trials. Amino Acids 45(6): 1273-1292. doi: 10.1007/s00726-013-1592-z. PMID: 24057808.

Seidlova-Wuttke, D., Ehrhardt, C., and Wuttke, W. 2010. Metabolic effects of 20-OH-ecdysone in ovariectomized rats. J. Steroid Biochem. Mol. Biol. 119(3-5): 121-126. doi:10.1016/j.jsbmb.2010.01.006. PMID: 20097286.

Toth, N., Hunyadi, A., Bathori, M., and Zador, E. 2010. Phytoecdysteroids and vitamin D analogues--similarities in structure and mode of action. Curr. Medicinal Chem. 17(18): 1974-94. doi: 10.2174/092986710791163911\#sthash.haJDqr9m.dpuf. PMID: 20377509.

\section{Toth, N., Szabo, A., Kacsala, P., Heger, J., and Zador, E. 2008. 20-Hydroxyecdysone increases} fiber size in a muscle-specific fashion in rat. Phytomed. Intl. J. Phytotherapy Phytopharmacol. 15(9): 691-698. doi: 10.1016/j.phymed.2008.04.015. PMID: 18585021. 
263 Wilborn, C.D., Taylor, L.W., Campbell, B.I., Kerksick, C., Rasmussen, C.J., Greenwood, M., et 264 al. 2006. Effects of methoxyisoflavone, ecdysterone, and sulfo-polysaccharide supplementation 265 on training adaptations in resistance-trained males. J. Intl. Soc. Sports Nutr. 3: 19-27. doi:

266 10.1186/1550-2783-3-2-19. PMID: 18500969.

267

268 


\section{Figure Legend}

270 Figure 1. Phosphorylation of Akt, mTOR and 4E-BP1 in the skeletal muscle of male rats orally

271 administered 20HE. Phosphorylated Akt at threonine 308 and total Akt expression was measured by

272 immunoblot in Study 1 (A), Study 2 (D) and Study 3 (G); Phosphorylated mTOR at serine 2448 and total

273 mTOR was measured by immunoblot in Study 1 (B), Study 2 (E) and Study 3 (H); Gel mobility shift

274 assay showing 4E-BP1 phosphorylation in Study 1 (C), Study 2 (F), and Study 3 (I). Bar graphs represent

275 means \pm SEM of densitometry ratios; $n=5-6$ per group. In Study 1 and 3, time of euthanasia was 30 min.

276 In Study 3, 20HE dose was $200 \mathrm{mg} / \mathrm{kg}$ and leucine dose was $1.35 \mathrm{~g} / \mathrm{kg}$. In each bar graph, means not

277 sharing a common letter are different, $\mathrm{P}<0.05$.

278

279

280

Figure 2. Phosphorylation of Akt, mTOR and 4E-BP1 in the liver of male rats orally administered 20HE.

281 Phosphorylated Akt at threonine 308 and total Akt expression was measured by immunoblot in Study 1

282 (A), Study 2 (D) and Study 3 (G); Phosphorylated mTOR at serine 2448 and total mTOR was measured

283 by immunoblot in Study 1 (B), Study 2 (E) and Study 3 (H); Gel mobility shift assay showing 4E-BP1

284 phosphorylation in Study 1 (C), Study 2 (F), and Study 3 (I). Bar graphs represent means \pm SEM of

285 densitometry ratios; n=5-6 per group. In Study 1 and 3, time of euthanasia was 30 min. In Study 3, 20HE

286 dose was $200 \mathrm{mg} / \mathrm{kg}$ and leucine dose was $1.35 \mathrm{~g} / \mathrm{kg}$. In each bar graph, means not sharing a common

287 letter are different, $\mathrm{P}<0.05$. 
A.
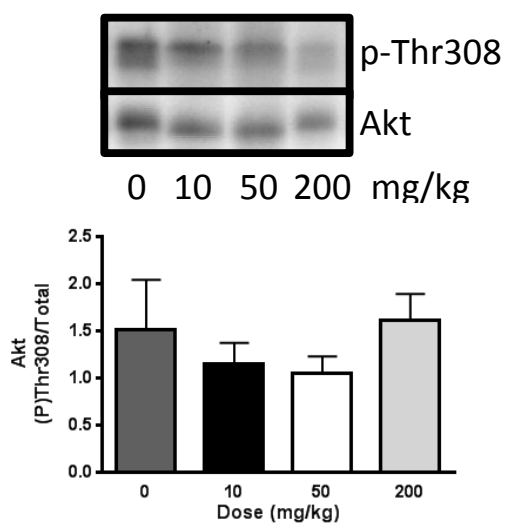

D.
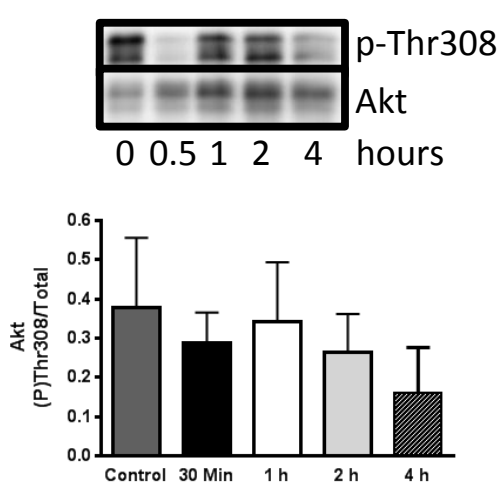

G.
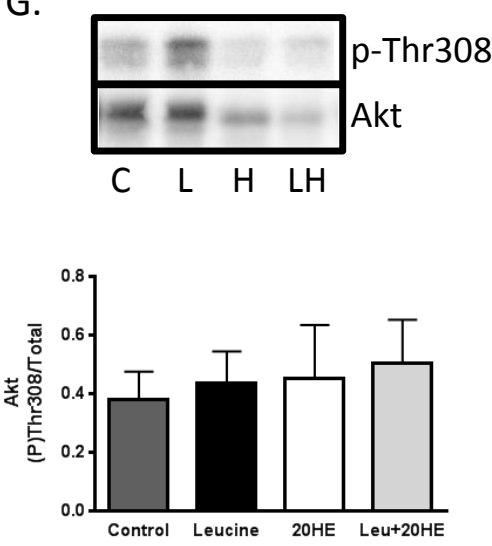

B.
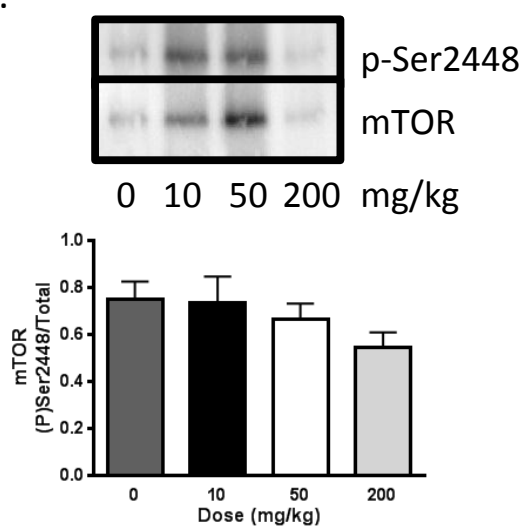

E.
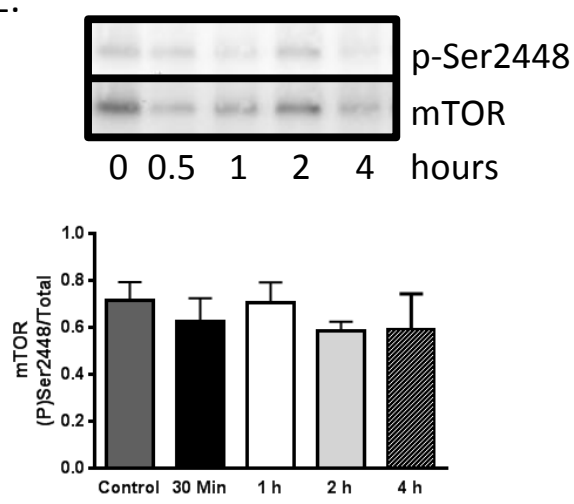

$\mathrm{H}$.
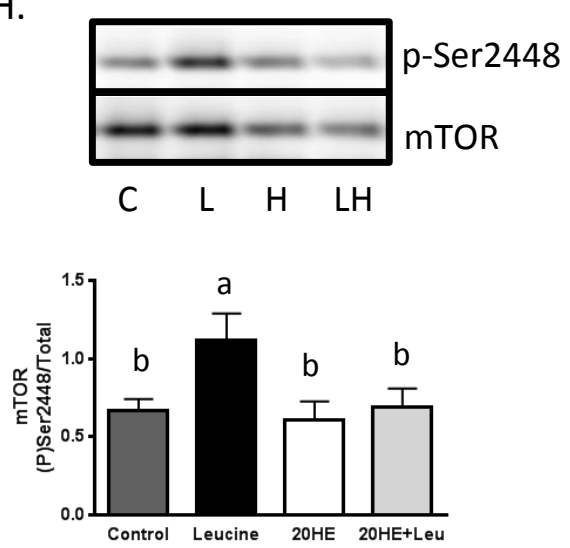

F.

C.
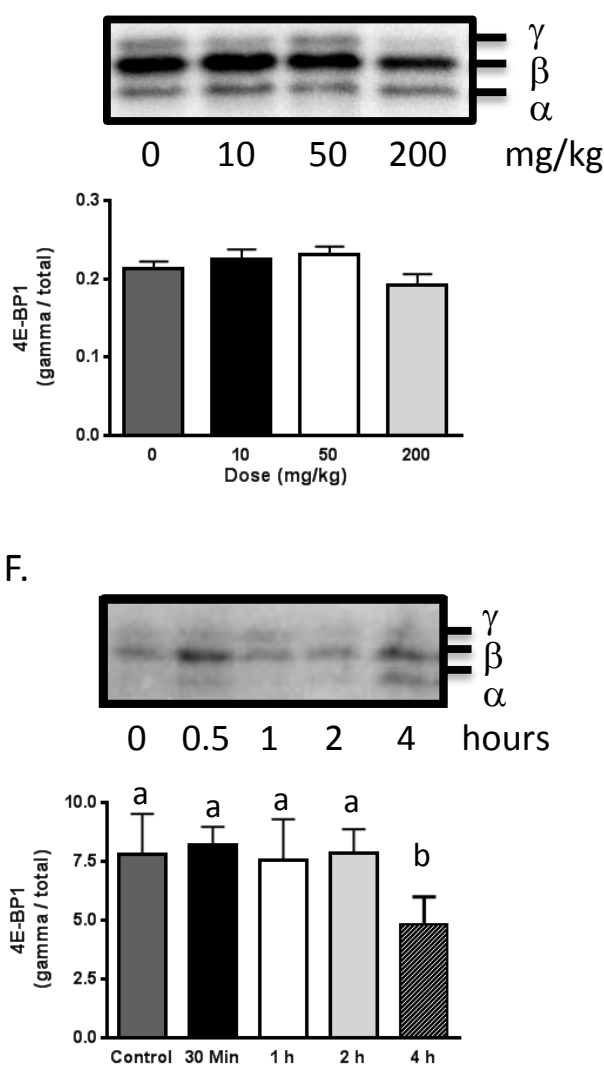

I.
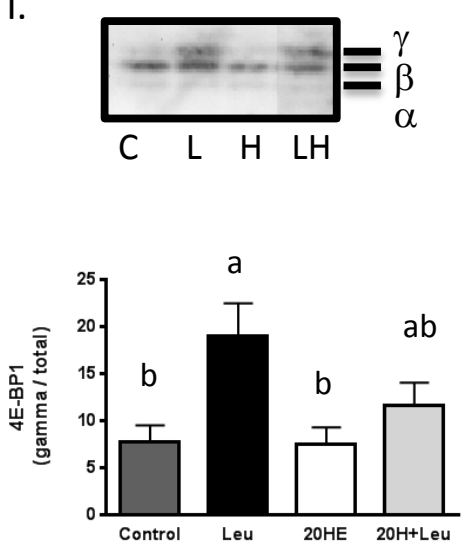
A.
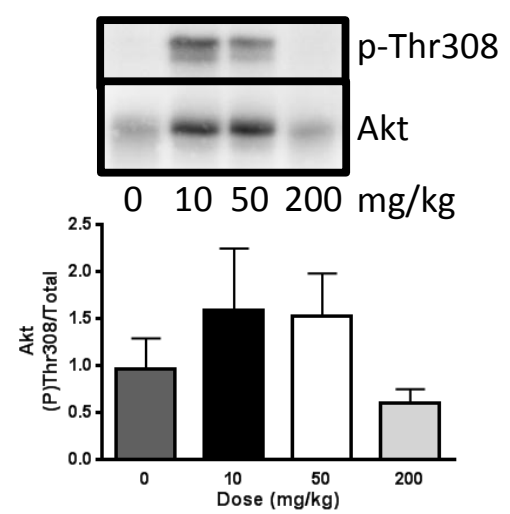

D.
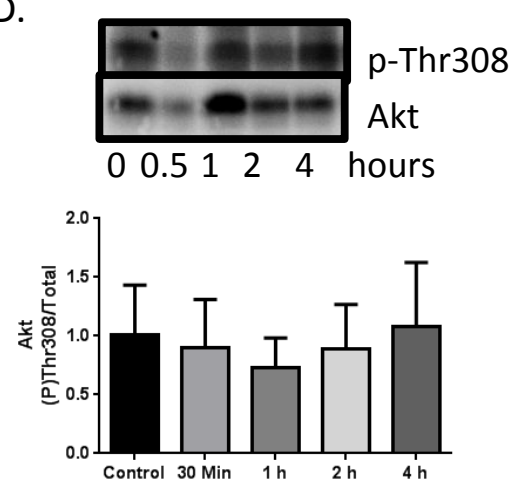

G.

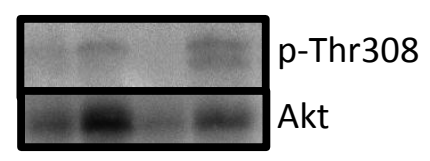

C $\quad$ L $\quad H \quad L H$

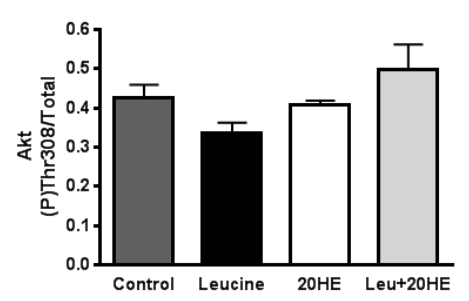

B.
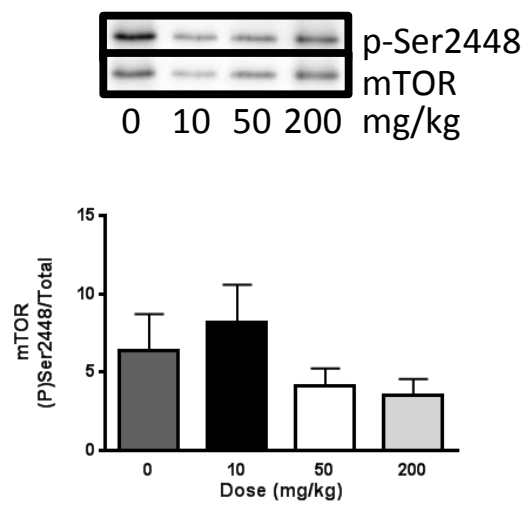

E.

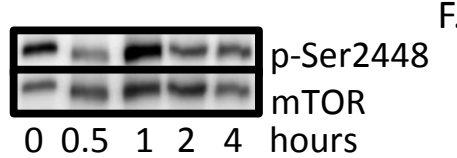

F.
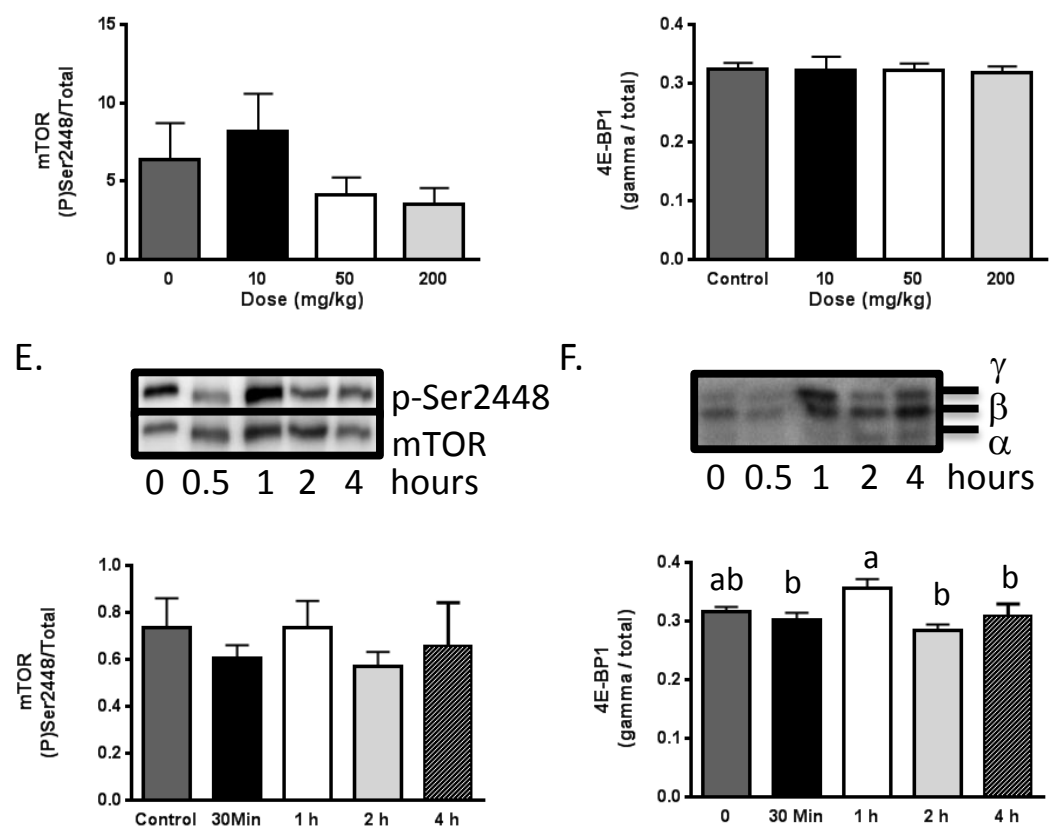

$\mathrm{H}$.

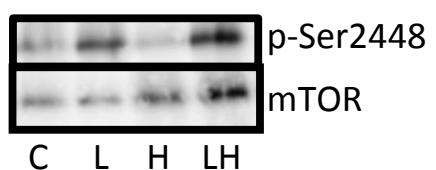

I.
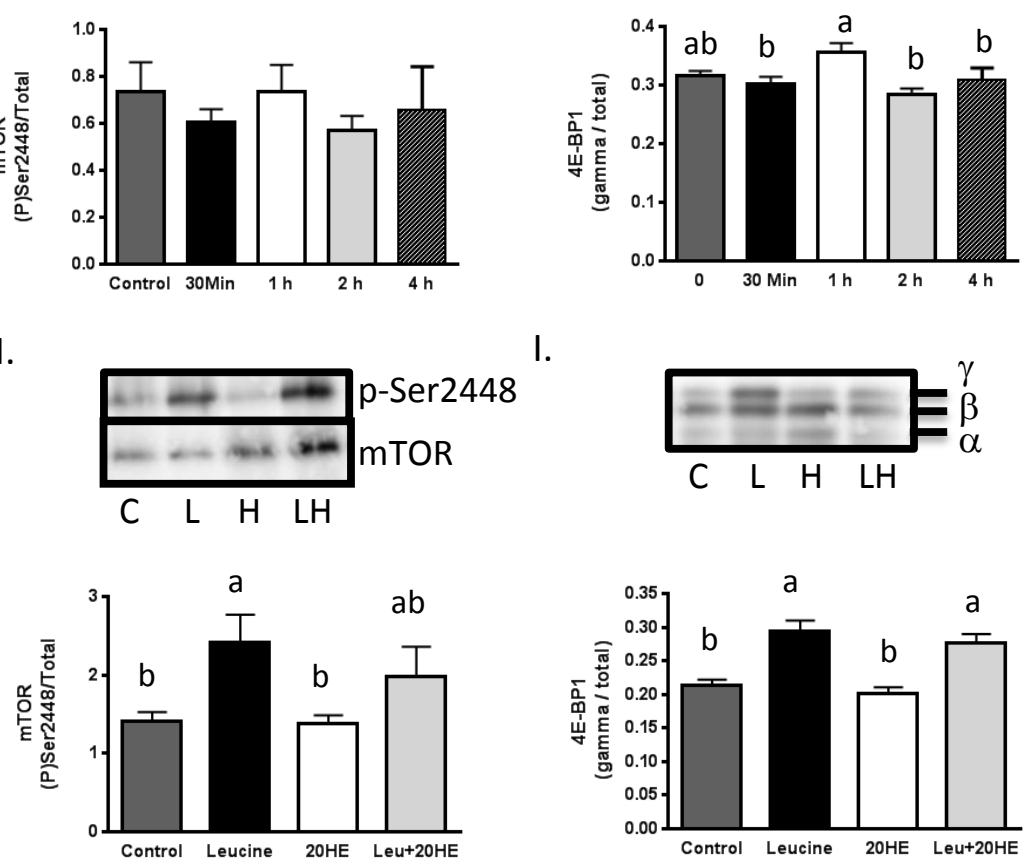